\title{
Os concursos públicos para professores de arte da educação básica privilegiam alguma linguagem artística?
}

Valéria Metroski de Alvarenga

\begin{abstract}
Resumo
É possível que as provas dos concursos públicos para professor de Arte da Educação Básica privilegiem alguma das quatro linguagens artísticas (Música, Dança, Teatro ou Artes Visuais) através de maior oferta de questões numa delas? Para respondermos essa pergunta, fizemos um levantamento das provas objetivas dos concursos públicos para professores de Arte da Rede Pública de Ensino realizados nos últimos dez anos (20032013) em 22 estados brasileiros. Após esse levantamento, verificamos se havia um tratamento igualitário do ponto de vista quantitativo na formulação das questões por parte das bancas examinadoras dos concursos públicos no que se refere às diferentes linguagens artísticas, visto que, atualmente, a maioria dos cursos de graduação em Arte no Brasil oferecem linguagens artísticas separadas. Constatamos que, em geral, os concursos continuam requisitando que o professor de Arte conheça as quatro linguagens artísticas e privilegia as Artes Visuais através de maior quantidade de questões nessa linguagem específica.
\end{abstract}

Palavras-chave: Concursos Públicos de Arte, Linguagens artísticas, Educação Básica.

\section{Does public tenure track for art teachers for elementary education privilege any artistic language?}

\section{Abstract}

It is possible that the evidence of public procurement for Art Teacher of Basic Education prioritize some of the four artistic languages (Music, Dance, Theatre and Visual Arts) through increased supply issues in one of them? To answer this question, we conducted a survey of objective evidence of public procurement for Art teachers of the Public Education Network conducted the last ten years (2003-2013) in 22 states. Following this survey, check if there were equal treatment from a quantitative point of view on the wording of the questions by the examination boards of public procurement in relation to the different artistic languages, as currently the most Art in undergraduate courses in Brazil offer separate artistic languages. We found that, in general, contests continue requesting that the Art teacher know the four artistic languages and favors the Visual Arts through increased amount of issues in that particular language.

Keywords: Public art Contest, Artistic languages, Basic Education.

\section{Introdução}

No presente artigo partimos da seguinte questão: é possível que as provas de processos seletivos em concursos públicos para professor do Ensino Fundamental II e/ou do Ensino Médio, na parte dos conhecimentos específicos da disciplina de Arte, privilegiem alguma das quatro linguagens artísticas (Música, Dança, Teatro ou Artes Visuais) através de maior oferta de questões numa destas linguagens? Para respondê-la, organizamos este 
artigo em diferentes tópicos. Ressaltamos que, apesar da divisão, eles se encontram intrinsecamente relacionados.

No tópico denominado (1) "Concurso público para professor de arte da Educação Básica", apresentaremos uma justificativa para a pesquisa realizada, a qual será feita através de um breve resumo que aponta as mudanças ocorridas no Ensino da Arte e, consequentemente, nos cursos de formação de professores para essa disciplina na Educação Básica. O marco inicial é a LDB 5.692/71, a qual instituiu a obrigatoriedade da "Educação Artística" na Educação Básica e, posteriormente, trataremos de algumas alterações ocorridas nos cursos de licenciatura na área de Arte até chegarmos às graduações de Música, Dança, Teatro e Artes Visuais. Para tal, utilizaremos artigos de Barbosa (1989), Alcântara (2012) e o Parecer das Diretrizes Curriculares Nacionais (DCN) para os cursos de Graduação em Artes Visuais (2007).

No segundo tópico intitulado (2) "Provas objetivas dos concursos públicos em Artes: linguagens associadas ou dissociadas?", justificaremos a pesquisa quantitativa com base nos textos da educadora Gatti (2011) e apresentaremos "o quê?" foi coletado, a saber: buscamos provas objetivas para a disciplina de arte nos concursos públicos para educação básica de todas as unidades federativas do Brasil (26 estados e 1 distrito federal) realizados entre os anos de 2003 e 2013. Selecionamos 22 provas pertencentes ao mesmo número de unidades federativas, sendo que essas últimas serão nosso objeto de análise. Ainda neste tópico realizaremos uma primeira análise das provas objetivas (verificando se as linguagens artísticas são ofertadas separadamente conforme a formação do inscrito ou de forma conjunta) e apresentaremos os conceitos de multidisciplinaridade, interdisciplinaridade e transdisciplinaridade baseados em Zabala (1998).

Já o tópico denominado (3) "Quando agregadas, a quantidade de questões para as diferentes linguagens artísticas é igual ou não?" corresponde à análise das provas objetivas dos concursos que ofertaram questões específicas de Arte de forma conjunta. Neste momento buscamos quantificar qual o número de questões destinadas às diferentes linguagens artísticas, com vistas a identificar se há ou não o privilégio de alguma linguagem sobre outra. Em função disto, construímos tabelas e gráficos para facilitar a visualização dos resultados obtidos. Elencada a estrutura do texto, vamos ao primeiro tópico. 


\section{Concurso público para professor de arte da Educação Básica}

O concurso público é uma das formas do professor ingressar na rede pública de ensino da Educação Básica e atuar como docente efetivo, tendo direito ao plano de carreira e outros benefícios aliados ao exercício da profissão. Normalmente, esse processo seletivo se divide em mais de uma fase, sendo elas: (1) prova objetiva; (2) prova discursiva; (3) prova didática e (4) prova de títulos. Nosso foco de análise restringe-se à prova objetiva, a qual geralmente possui uma parte com "questões diversas" denominadas conhecimentos gerais, outra dedicada aos conhecimentos pedagógicos e, por fim, os conhecimentos específicos da área em que o candidato inscrito pretende atuar. Mas, por que analisar quantitativamente o direcionamento dado às provas objetivas dos concursos públicos para Educação Básica na parte específica de Arte?

Para responder tal questão teremos que fazer um pequeno relato. A autora realizou um concurso público para professor de Arte na Educação Básica no Estado do Paraná e se deparou com questões de todas as linguagens artísticas, sendo que havia maior oferta de questões referentes à visualidade. A autora conseguiu realizar a prova, pois devido a sua formação em Artes Visuais, ela não se sentiu prejudicada. Porém, dois colegas que atuavam no mesmo colégio ${ }^{1}$ juntamente com a autora, um formado em Música e outro formado em Teatro, ambos graduados e lecionando Arte há vários anos, não conseguiram obter bons resultados na prova objetiva por haver um mínimo de questões nas suas respectivas linguagens artísticas de formação. Após esse acontecimento, a autora decidiu verificar se o fato ocorria apenas no Estado do Paraná ou se acontecia ao nível nacional, com o intuito de, em caso afirmativo, pudesse vir a propor alternativas para que o professor-candidato não saia prejudicado nas provas dos concursos públicos devido a sua linguagem específica de formação. Além disso,

As discussões, em geral, sobre concursos públicos para professores de artes vêm gradualmente aumentando no espaço virtual da FAEB, sejam impulsionadas por docentes já efetivados no serviço público ou mesmo por graduados que almejam tornarse concursados. Esses debates registram a preocupação da categoria na ocupação de seus cargos em processos seletivos por docentes de outras áreas (como Educação Física na área da Dança) e também do grande número de avaliações que exigem um docente em arte polivalente. Com os avanços e conquistas do ensino de arte no Brasil, nos campos teórico, documental (PCNs, LDB, etc.) e formativo profissional, esperava-se que tais desenvolvimentos fossem refletidos também nos processos seletivos ocorridos no nosso país. (ALCÂNTARA, 2012, pp. 411412).

\footnotetext{
${ }^{1}$ Todos com contrato temporário, inclusive a autora.

2 "O currículo de Licenciatura em Educação Artística na universidade pretende preparar um professor de arte Revista Digital do LAV - Santa Maria - vol. 8, n.4, p. 105-121 - Jan./Abr.2015 ISSN 1983-7348 
Como ressalta Alcântara (2012) os avanços e conquistas na área de arte no Brasil não atingiram, em geral, os concursos públicos para professores de Arte que irão atuar na Educação Básica, mas as discussões sobre essa temática vêm se ampliando. Esse mesmo autor realizou uma pesquisa sobre os concursos públicos ocorridos em "Pernambuco entre os anos de 2009 a 2011, nas esferas municipais, que designaram vagas para o cargo de 'professor de arte'"' (ALCÂNTARA, 2012, p. 412) e constatou que:

\begin{abstract}
a não especificação em todas essas avaliações da linguagem a ser ministrada (com exceção de algumas que distinguiram a música, porém generalizando as outras linguagens) propõe assim a concorrência nestes procedimentos avaliativos entre professores com formação nas mais diversas linguagens para ocupação da mesma vaga. (ALCÂNTARA, 2012, p. 412).
\end{abstract}

Vemos, portanto, que a pesquisa realizada por Alcântara evidencia algo semelhante ao que a autora relatou acima a respeito do concurso público no Estado do Paraná. Visto que a indefinição de qual profissional e/ou linguagem específica é desejada pela instituição que realiza o concurso ao apresentar a designação "professor de arte", pessoas formadas nas quatro linguagens artísticas separadamente ou em cursos de Arte polivalentes se candidatam às vagas. "Diante dessa situação, surge o seguinte questionamento: como as questões elaboradas construíram um formato coerente de exigir conhecimento específico na área de formação do docente?" (ALCÂNTARA, 2012, p.412). A questão levantada por esse autor vai ao encontro das nossas.

Antes de analisarmos as provas dos concursos, verificamos algumas diretrizes e leis que interferiram na oferta das linguagens artísticas no Ensino Superior. Constatamos que, segundo dados do INEP/MEC, hoje a maioria das licenciaturas na área de Arte oferece cursos em linguagens artísticas separadamente. Mas, nem sempre isso foi assim. A LDB 5.692/71 instituiu a obrigatoriedade do ensino da Arte na Educação Básica, o que gerou um aumento dos cursos de graduação nessa área, assim como o fenômeno da polivalência:

Tal obrigatoriedade fez crescer a oferta de graduações (sobretudo licenciatura) com habilitações em Artes Plásticas, Artes Cênicas, Música e Desenho (...). Entretanto, aquela Lei também instituiu a polivalência, sob o princípio de que o professor de artes deveria ser um generalista e não um especialista em cada linguagem artística. (PARECER DCN-Artes Visuais, 2007, pp. 1-2). 
Cursos de curta duração, sobre todas as linguagens artísticas ${ }^{2}$, foram criados para suprir a demanda educacional que surgiu após a obrigatoriedade da Educação Artística, porém esses apresentaram problemas, pois tal como afirma Barbosa: "é um absurdo epistemológico ter a intenção de transformar um jovem estudante (...) com um curso de apenas dois anos, num professor de tantas disciplinas artísticas." (1989, p. 171).

Para tentar resolver algumas questões que foram surgindo devido a esta formação, várias associações foram criadas, dentre elas a Federação de Arte Educadores (FAEB). Tais associações conseguiram construir "um referencial considerável sobre o ensino da arte e a formação de profissionais na área. Toda essa intensa mobilização redundou num outro perfil para o ensino da arte na educação básica e, consequentemente, para os cursos superiores de arte" (PARECER DCN-Artes Visuais, 2007, p. 2). Após uma melhor definição e estruturação do ensino de arte através da LDB 9.394/96, alterando a noção de 'atividade', contida na LDB 5.692/71, para 'disciplina', assim como a modificação da nomenclatura 'Educação Artística' para 'Arte' e também com a criação das DCN com linguagens artísticas separadas, os antigos cursos de Educação Artística sofreram alterações, tal como podemos ver no parecer que se segue:

O Parecer CNE/CES no 195/2003, aprovado em 5/8/2003 e publicado em 12/2/2004, trata das Diretrizes Curriculares Nacionais dos Cursos de graduação em Música, Dança, Teatro e Design ${ }^{3}$, refletindo o referencial acumulado pelos profissionais da área no sentido de que a formação em curso superior contemple a especificidade das linguagens artísticas - e não mais a polivalência e a generalidade preconizadas pela Lei no 5.692/71. (PARECER DCNArtes Visuais, 2007, p. 3 - itálico nosso).

Vemos, portanto, que os cursos de graduação em linguagens artísticas separadas existem há, no mínimo, uma década. Resumindo, inicialmente a formação do professor de arte contemplava as quatro linguagens artísticas e possuía curta duração (dois anos) e, após intensas lutas e união de forças de associações de diferentes linguagens artísticas, consegue-se que os cursos de licenciatura em Arte ofertem linguagens artísticas separadas com duração média de quatro anos, tal como no momento atual. É importante ressaltar que, segundo pesquisas realizadas pelo projeto do "Observatório da Formação de Professores no âmbito do Ensino de Arte: estudos comparados entre Brasil e Argentina" através de dados oriundos do INEP/MEC, ainda existem cursos com as

\footnotetext{
2 "O currículo de Licenciatura em Educação Artística na universidade pretende preparar um professor de arte em apenas dois anos, que seja capaz de lecionar música, teatro, artes visuais, desenho, dança e desenho geométrico, tudo ao mesmo tempo, da la à $8^{a}$ série $s$ e, em alguns casos, até o $2^{\circ}$ grau." (BARBOSA, 1989, pp. 170-171).

${ }^{3}$ As DCN dos cursos de graduação em Artes Visuais foram aprovadas em 2009.
}

Revista Digital do LAV - Santa Maria - vol. 8, n.4, p. 105-121 - Jan./Abr.2015 ISSN 1983-7348 
nomenclaturas 'Artes', 'Educação Artística' e 'Arte-educação' em atividade no Brasil. Estes, em geral, ainda ofertam as quatro linguagens artísticas. A maior parte dos cursos de licenciatura, no entanto, já ofertam linguagens artísticas separadamente. Considerando esses fatores é que perguntamos:

\section{Provas objetivas dos concursos públicos em Artes: linguagens artísticas associadas ou dissociadas?}

Quais são os aspectos favoráveis e contrários à oferta das questões dos concursos com as quatro linguagens artísticas de forma conjunta e/ou separadas? Ao abordarmos essa questão entramos em discussões polêmicas como, por exemplo, a supervalorização da interdisciplinaridade e da transdisciplinaridade, mesmo com uma estrutura curricular na educação básica e no ensino superior, em geral, multidisciplinar. Para compreendermos melhor esses conceitos recorremos aos textos de Zabala (1998), o qual afirma que para a ciência compreender a realidade teve de fragmentar o saber diversificando o conhecimento numa grande quantidade de disciplinas e, assim, cada qual foi criando um corpo diferenciado e especializado, determinando campos de conhecimento, materiais de referência, metodologias, instrumentos de análise e aplicações práticas próprias. No entanto, muitas vezes essas disciplinas se relacionam de maneiras distintas. Zabala (1998) apresenta três formas básicas, a saber: multidisciplinaridade, interdisciplinaridade e transdisciplinaridade e as define do seguinte modo:

A multidisciplinaridade é a organização de conteúdos mais tradicional. Os conteúdos escolares são apresentados por matérias independentes umas das outras. O conjunto de matérias ou de disciplinas é proposto simultaneamente, sem que apareçam explicitamente as relações que podem existir entre elas. A interdisciplinaridade é a interação entre duas ou mais disciplinas, que pode ir desde a simples comunicação de ideias até a integração recíproca dos conceitos fundamentais e da teoria do conhecimento, da metodologia e dos dados da pesquisa. A transdisciplinaridade é o grau máximo de relações entre as disciplinas, daí que supõe uma integração global dentro de um sistema totalizador. Esse sistema fornece uma unidade interpretativa, com o objetivo de construir uma ciência que explique a realidade sem parcelamento. (ZABALA, 1998, pp.143144).

Considerando essas formas de relação entre as disciplinas é importante apresentarmos alguns exemplos de questões das provas objetivas dos concursos que evidenciam, através de seu conteúdo, que a maioria delas exibem um caráter multidisciplinar, ou seja, o fato de haver questões de todas as linguagens artísticas na mesma prova 
(ofertadas de forma conjunta) não significa que elas possuem características interdisciplinares e/ou transdisciplinares, tal como podemos observar:

A institucionalização da dança no Brasil ocorreu no Rio de Janeiro, com o balé clássico, e se estendeu para outras capitais, tais como: (a) Salvador, onde foi instituída a primeira faculdade de dança do Brasil; (b) Fortaleza, onde surgiu o Colégio de Danças Populares do Dragão do Mar; (c) Brasília, onde foram criadas a Cia. Dos Homens e o Grupo Experimental de Dança; (d) Curitiba, onde surgiu o Basirah e a Gril Cia de Dança; (e) São Paulo, onde se fundou o Balé Klauss Viana. (CEARÁ, 2013, questão no 65).

Mais um exemplo de questão que é específica de uma linguagem artística, e muito pontual, pode ser vista abaixo:

Assinale a alternativa em que NÃO há relação correta do gênero musical e do conceito: (a) Cantata - Peça cantada, na qual uma pessoa recitava um drama em verso acompanhada por um instrumento musical; (b) Fuga - Composição polifônica que desenvolvia largamente um mesmo tema, de forma variada; (c) Réquiem - Composição de característica popular, melodiosa, folclórica e alegre; (d) Tocata - Forma livre de composição musical para instrumento de teclado; (e) Suíte - Sequência de danças executadas na Renascença por conjuntos musicais no mesmo tom. (PARÁ, 2010, questão n037).

Esses são exemplos de questões que não buscam a interdisciplinaridade e/ou a transdisciplinaridade, evidenciando uma caraterística multidisciplinar das questões das provas, as quais exigem conhecimento específico de determinadas linguagens artísticas, ou seja, quem cursou Artes Visuais, por exemplo, dificilmente saberia responder a essas questões devido à forma como elas foram elaboradas e por sua delimitação e especificidade. Ao verificarmos outras questões dos concursos observamos que o oposto também ocorre, pois em algumas provas as questões buscam pontos em comum entre as quatro linguagens artísticas, através de um entendimento do que é arte ou ensino de arte, tal como o exemplo a seguir:

Pensar a disciplina Arte em um processo de formação continuada de professores pressupõe estabelecer uma articulação com os três eixos norteadores estabelecidos pelos PCN's: produzir, apreciar e contextualizar. Assinale a alternativa que descreve corretamente as orientações curriculares da disciplina Arte em seus eixos norteadores: (a) O produzir se refere à fruição de arte e do universo a ela relacionado, possibilitado pela realização de atividades que articulam educação artística e museologia; (b) 0 contextualizar consiste em analisar a produção artística individual e do outro, decodificando seus elementos compositivos e simbólicos em oficinas de atualização metodológica; (c) O apreciar é a decodificação e fruição da arte, através da análise dos atributos estéticos que uma sociedade associa às manifestações 
artísticas; (d) O fazer artístico é o processo de aquisição de competências técnicas obtidas mediante o exercício da imitação das obras dos grandes mestres; (e) E) O apreciar é ação de inserir o próprio trabalho artístico no contexto social, histórico e cultural ao qual se refere. (SÃO PAULO, 2013, questão no 7).

Tendo por base os exemplos acima, notamos que, muitas vezes, sob o discurso da interdisciplinaridade e/ou transdisciplinaridade, assim como pela falta de especificidade do que é entendido pela palavra 'arte' na atual LDB, temos provas objetivas nos concursos públicos para professor de arte com caráter multidisciplinar contemplando as quatro linguagens artísticas, as quais prejudicam os egressos dos cursos de licenciatura com linguagem artística específica. E mesmo as questões que buscam relações entre as quatro linguagens artísticas podem ser problemáticas ${ }^{4}$ quando consideramos que nem sempre os discentes vivenciam durante a graduação essa interdisciplinaridade e/ou transdisciplinaridade em relação às outras linguagens artísticas. Por outro lado, se a articulação entre as diversas linguagens artísticas ocorressem de modo satisfatório na formação inicial, algumas questões com essas características gerais poderiam ser contempladas nas provas dos concursos para realçar os aspectos comuns existentes entre elas, os quais ultrapassam suas singularidades.

Concordamos com a oferta de cursos de licenciatura em linguagens artísticas separadas, porém, se o futuro professor tem acesso aprofundado em apenas uma linguagem artística, por que na prova do concurso ele precisa "saber/conhecer" todas ${ }^{5}$ ? Nessa pergunta encontra-se embutida parte do resultado da nossa análise.

Antes de apresentarmos os dados coletados, se faz necessário justificar o método de análise da nossa pesquisa. Utilizaremos dados quantitativos, pois "(...) há problemas educacionais que, para sua contextualização e compreensão, necessitam ser qualificados através de dados quantitativos." (GATTI, 2011, p. 79). Afinal, como afirma esta mesma autora:

\footnotetext{
${ }^{4}$ No exemplo acima a questão pode ser respondida por uma pessoa formada em qualquer uma das quatro linguagens artísticas porque ela aborda um conhecimento geral sobre o ensino de arte, porém há outras questões que buscam uma relação interdisciplinar entre duas linguagens artísticas ou mais. Colocamos nas referências os links das três provas que retiramos as questões que mostramos como exemplo, ou seja, se o leitor tiver interesse poderá verificar o conteúdo das provas na íntegra e como ocorre (quando ocorre) essa interdisciplinaridade e/ou transdisciplinaridade. Também disponibilizamos o link do PCI Concursos onde o leitor poderá acessar todas as provas analisadas, as quais estão especificadas na tabela 2.

5 E essa exigência não ocorre apenas nas provas dos concursos, ainda hoje, devido a indefinição de conteúdos na disciplina de Arte na Educação Básica, muitas vezes os professores de Arte, formados numa linguagem específica são "incentivados" a ensinar todas as linguagens sem a devida formação. Já existe um projeto de lei que pretende resolver esse problema. Ele é problematizado por ALVARENGA (2013) no artigo intitulado: "O projeto de lei 7.032/10 prevê linguagens artísticas separadas na Educação Básica: será o fim da polivalência?" Disponível em: http://proxy.furb.br/ojs/index.php/linguagens/article/view/4067/2593 Acesso em: 10/06/2014.
} 
Os métodos de análise de dados que se traduzem por números podem ser muito úteis na compreensão de diversos problemas educacionais. Mais ainda, a combinação desse tipo de dados com dados oriundos de metodologias qualitativas, podem vir a enriquecer a compreensão de eventos, fatos, processos. (GATTI, 2011, p. 80).

No que diz respeito aos métodos de análise, nossa pesquisa tem uma base quantitativa. Os métodos quantitativos e qualitativos, no entanto, se entrelaçam quando fica evidente que as questões das provas foram contabilizadas de acordo com alguns critérios que escolhemos para "interpretar" qual o direcionamento dado às mesmas. Veremos isso no próximo tópico.

Neste momento (i) apresentaremos a quantidade total de provas analisadas, (ii) o ano em que esses concursos foram realizados e (iii) se as provas objetivas eram ofertadas com as linguagens artísticas dissociadas ou de forma associada.

(i) Buscamos provas objetivas ${ }^{6}$ de concursos públicos, para professor de Arte da Educação Básica, nas 27 unidades federativas do Brasil através do site do PCI Concursos $^{7}$. Encontramos 22 provas ofertadas pelo mesmo número de unidades federativas, as quais foram realizadas entre os anos de 2003 e $2013^{8}$. Encontramos também diversas provas ofertadas pelas prefeituras, porém, como elas são específicas de uma cidade e não contemplam todo o estado, preferimos não analisá-las. No próximo tópico apresentaremos mais elementos sobre as provas coletadas.

(ii) No que se refere ao ano em que os concursos foram realizados, organizamos uma pequena tabela para facilitar a visualização, tal como podemos ver abaixo:

Tabela. 01 - Ano de realização dos concursos

\begin{tabular}{|l|c|c|c|c|c|c|c|c|c|c|}
\hline $\begin{array}{l}\text { Ano de } \\
\text { realização }\end{array}$ & 2003 & 2006 & 2007 & 2008 & 2009 & 2010 & 2011 & 2012 & 2013 & Total \\
\hline $\begin{array}{l}\text { Quantidade } \\
\text { de provas }\end{array}$ & 1 & 1 & 1 & 1 & 3 & 3 & 3 & 4 & 5 & 22 \\
\hline
\end{tabular}

Fonte: Tabela elaborada pela autora com base nas provas objetivas coletadas

\footnotetext{
${ }^{6}$ Em formato PDF.

${ }^{7} \mathrm{PCI}$ Concursos, disponível em: http://www.pciconcursos.com.br/provas/professor-de-arte. Acesso em: 08/02/2015.

${ }^{8} \mathrm{Em}$ alguns estados encontramos mais de uma prova referente a concursos públicos para professor de arte, pois esses realizaram mais de um concurso no período de tempo analisado. Para contemplar o máximo possível de estados de forma igualitária, quando um estado apresentava mais de um concurso, escolhíamos a prova mais recente.
} 
A partir da tabela 1 é possível perceber que buscamos contemplar os concursos mais recentes (18 provas), e ainda assim consideramos provas de quatro (4) concursos realizados antes de 2009. Acreditamos que o período escolhido é coerente com os apontamentos realizados anteriormente sobre a separação das linguagens artísticas no ensino superior, a qual foi impulsionada pelo surgimento das DCN das quatro linguagens artísticas individuais.

(iii) Assim que coletamos os dados já foi possível detectar quais estados ofertaram as provas com linguagens artísticas separadas, pois havia arquivos separados de acordo com as linguagens artísticas. Apenas dois estados ofertaram provas considerando a linguagem de formação do inscrito, a saber: Acre (2013) e Goiás (2010). Constatamos que apesar do Estado do Acre ofertar provas separadas para a disciplina de Arte, este estado desconsiderou a linguagem da Dança, ou seja, as provas objetivas contemplaram apenas as Artes Visuais, a Música e as Artes Cênicas/Teatro. Já o Estado de Goiás considerou as quatro linguagens artísticas. Realizamos um gráfico, com base nas provas coletadas, evidenciando quão pequena é a quantidade de estados que ofertaram provas de acordo com a linguagem de formação do inscrito, tal como podemos ver abaixo:

\section{Gráfico. 01 - Provas objetivas dos concursos públicos para a disciplina de Arte na Educação Básica (associadas e dissociadas)}

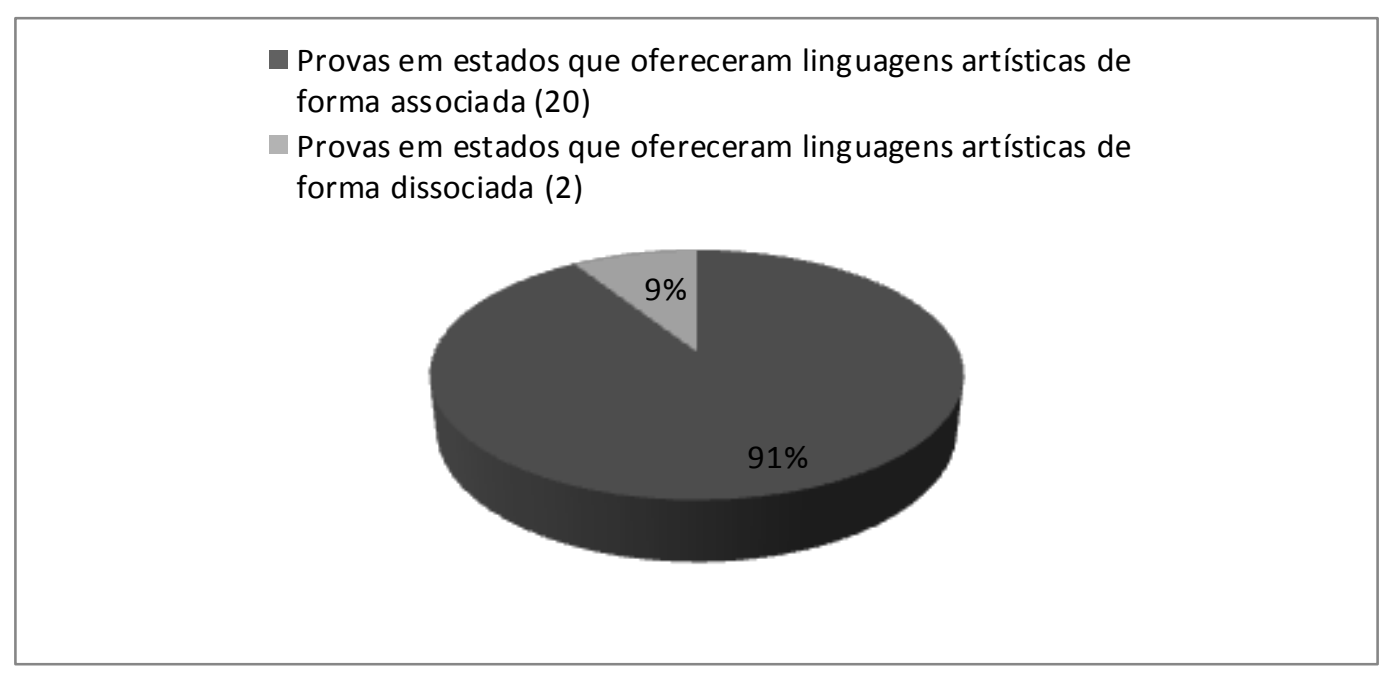

Fonte: Gráfico elaborado pela autora com base nas provas objetivas coletadas

Com base no gráfico 1 , vemos que a maioria dos estados brasileiros, oferecem provas com linguagens artísticas associadas (91\%) desconsiderando a linguagem de formação do inscrito, sendo que apenas ( $9 \%$ ) ofertou provas separadas. Com base nesses dados, outra indagação se apresenta: será que a quantidade de questões, nas provas objetivas que oferecem as quatro linguagens de forma conjunta, é equilibrada ou será que alguma 
linguagem artística tem um maior número de questões, o que privilegiaria uma determinada linguagem de formação?

\section{Quando agregadas, a quantidade de questões para as diferentes linguagens artísticas é igual ou não?}

Para respondermos essa pergunta tivemos que criar critérios de análise para uma possível "tradução numérica" 9 " do direcionamento dado às questões das 20 provas onde as quatro linguagens artísticas apareciam associadas. É importante ressaltar que nosso objetivo não é analisar o conteúdo das questões, mas sim quantificarmos as mesmas de acordo com as quatro linguagens artísticas. Com o intuito de minimizar a interferência subjetiva durante a análise/interpretação das mesmas, elaboramos 'palavras-chave' para colocarmos em diferentes categorias a referência básica (o direcionamento) dos conteúdos das questões, a saber:

(1) Artes Visuais: classificamos questões que tinham no título Artes Visuais, Artes Plásticas, Cultura Visual, pintores, escultores, leitura de imagem, performance, Land Art, vídeo-arte, instalação, body art, fotografia, assemblage, arte conceitual, grafite, hiperrealismo, intervenção urbana, gravura e diferentes técnicas da mesma, movimentos artísticos que faziam referência direta a visualidade, tais como impressionismo, cubismo, etc., entre outras questões com o mesmo enfoque.

(2) Música: consideramos a palavra Música contida no título ou na relação entre perguntas e respostas, assim como a Lei $11.769 / 2008^{10}$, questões que priorizavam o som, elementos formais de música e outras questões similares.

(3) Dança: para essa opção, utilizamos como base a palavra Dança presente no título ou na relação direta entre pergunta e possíveis respostas, entre outras questões semelhantes.

(4) Teatro: elencamos, nesta categoria, questões que afirmavam no título ou no conjunto da relação pergunta/respostas, palavras como: teatro, artes cênicas, jogos teatrais, elementos formais do teatro, figurino, cenário, figurante, protagonista, entre outras semelhantes.

\footnotetext{
9 "O que se procura ao criar uma tradução numérica ou categorial de fatos, eventos, fenômenos é que essa tradução tenha algum grau de validade racional, teórica, no confronto com a dinâmica observável dos fenômenos." (GATTI, 2011, p. 82).

${ }^{10} \S 6$. A música deverá ser conteúdo obrigatório, mas não exclusivo, do componente curricular de que trata o $\S 2$ deste artigo. (Incluído pela Lei no 11.769, de 2008). O parágrafo segundo do artigo 26 da atual LDB referese à obrigatoriedade do ensino da arte.
} 
(5) Ensino de Arte/Leis: nesta categoria colocamos questões relacionadas aos Parâmetros Curriculares Nacionais de Arte (PCN-Arte), LDB 5.692/71, LDB 9.394/96, Diretrizes e Propostas curriculares para o Ensino da Arte nos diferentes estados brasileiros, questões referentes a currículo, avaliação de arte, papel do professor, função da arte na escola, entre outras questões parecidas.

(6) Gerais: reservamos esse espaço para questões que tratavam sobre estética, função da arte, patrimônio histórico, artesanato típico do Estado que ofertou a prova, entre outras questões com características similares.

Com base nesses critérios, construímos a tabela 2, a qual contempla o nome do Estado (por ordem alfabética), o número de questões ofertadas especificamente para a disciplina de Arte, as quatro linguagens artísticas (Artes Visuais, Música, Teatro e Dança), Ensino de Arte/Leis, "Gerais", ano de realização do concurso e se a oferta das linguagens artísticas na prova objetiva era de forma conjunta ou não, tal como podemos observar a seguir:

Tabela. 02 - Concurso Público - Arte - Quantidade de questões ofertadas

\begin{tabular}{|c|c|c|c|c|c|c|c|c|c|}
\hline Estado & $\begin{array}{c}\text { Total de } \\
\text { questões } \\
\text { específicas }\end{array}$ & $\begin{array}{c}\text { Artes } \\
\text { Visuais }\end{array}$ & Música & Teatro & Dança & $\begin{array}{l}\text { Ensino da } \\
\text { Arte/Leis }\end{array}$ & Gerais & Ano & $\begin{array}{l}\text { Linguagens } \\
\text { artísticas: } \\
\text { (A) } \\
\text { associadas } \\
\text { ou (D) } \\
\text { dissociadas }\end{array}$ \\
\hline Acre & ----- & 40 & 40 & 40 & 0 & ----- & ----- & 2013 & $\mathrm{D}$ \\
\hline Alagoas & ----- & ----- & ----- & ----- & ----- & ----- & ----- & ----- & ----- \\
\hline Amapá & 25 & 6 & 7 & 7 & 0 & 3 & 2 & 2012 & $A$ \\
\hline Amazonas & 15 & 6 & 1 & 1 & 3 & 2 & 2 & 2011 & $A$ \\
\hline Bahia & ----- & ----- & ----- & ----- & ----- & ----- & ----- & ----- & ----- \\
\hline Ceará & 50 & 22 & 7 & 4 & 6 & 6 & 5 & 2013 & $A$ \\
\hline Distrito Federal & 13 & 0 & 3 & 0 & 0 & 3 & 7 & 2006 & $\mathrm{~A}$ \\
\hline Espírito Santo & 15 & 8 & 0 & 0 & 0 & 2 & 5 & 2010 & $A$ \\
\hline Goiás & ----- & 20 & 20 & 20 & 20 & ----- & ----- & 2010 & $\mathrm{D}$ \\
\hline Maranhão ${ }^{11}$ & 30 & 19 & 2 & 6 & 0 & 0 & 3 & 2009 & $\mathrm{~A}$ \\
\hline Mato Grosso & 25 & 9 & 4 & 1 & 2 & 8 & 1 & 2007 & A \\
\hline Mato Grosso do Sul & ----- & ----- & ----- & ----- & ----- & ----- & ----- & ----- & ----- \\
\hline Minas Gerais & 40 & 21 & 4 & 1 & 0 & 12 & 2 & 2012 & $A$ \\
\hline Paraná & 20 & 4 & 2 & 1 & 0 & 11 & 2 & 2013 & A \\
\hline Paraíba & 20 & 14 & 1 & 1 & 1 & 2 & 1 & 2011 & $A$ \\
\hline Pará & 20 & 8 & 4 & 2 & 0 & 2 & 4 & 2009 & $A$ \\
\hline Pernambuco & 40 & 12 & 1 & 0 & 1 & 23 & 3 & 2008 & $A$ \\
\hline Piauí & 20 & 8 & 4 & 4 & 1 & 1 & 2 & 2012 & $A$ \\
\hline Rio de Janeiro & 30 & 4 & 7 & 9 & 0 & 9 & 1 & 2010 & $A$ \\
\hline Rio Grande do Norte & 35 & 22 & 3 & 5 & 1 & 2 & 2 & 2011 & $\mathrm{~A}$ \\
\hline Rio Grande do Sul & ----- & ----- & ----- & ----- & ----- & ----- & ----- & ----- & ----- \\
\hline Rondônia & 15 & 5 & 3 & 2 & 2 & 2 & 1 & 2013 & A \\
\hline Roraima & ----- & ----- & ----- & ----- & ----- & ----- & ----- & ----- & ----- \\
\hline Santa Catarina & 20 & 16 & 1 & 1 & 0 & 1 & 1 & 2012 & $\mathrm{~A}$ \\
\hline
\end{tabular}

${ }^{11}$ Este estado realizou provas diferentes para o Ensino fundamental II e para o Ensino Médio. Analisamos a prova referente ao Ensino Médio. 


\begin{tabular}{|c|c|c|c|c|c|c|c|c|c|}
\hline Sergipe & 30 & 13 & 2 & 2 & 2 & 5 & 6 & 2003 & $A$ \\
\hline São Paulo & 30 & 9 & 6 & 6 & 6 & 3 & 0 & 2013 & A \\
\hline Tocantins & 30 & 7 & 1 & 4 & 0 & 9 & 9 & 2009 & A \\
\hline
\end{tabular}

Fonte: Tabela elaborada pela autora com base nas provas objetivas coletadas

Sobre os dados da tabela acima, informamos que são apresentados dados de 22 estados, mas, como vimos anteriormente, dois ofereceram provas objetivas de acordo com a linguagem de formação do inscrito e por esse motivo eles não serão contabilizados. Analisaremos, portanto, a quantidade de questões de 20 provas objetivas que ofertaram as quatro linguagens de forma conjunta, as quais pertencem a 20 estados brasileiros distintos.

A tabela 2 apresenta inúmeras possibilidades de análise. Porém, com o intuito de verificar se há ou não privilégio de alguma linguagem artística quando elas são ofertadas de modo associado, consideraremos apenas as questões referentes às quatro linguagens artísticas (Música, Teatro, Dança e Artes Visuais).

Como o número de questões específicas para a disciplina de Arte varia de estado para estado, assim como de ano para ano, consideramos a relação existente entre a quantidade de questões nas quatro linguagens artísticas para verificarmos se alguma delas teve maior número de questões e se havia ou não equilíbrio entre elas. Computamos os dados e constatamos o seguinte:

Tabela. 03 - Maior oferta de questões por linguagem artística

\begin{tabular}{|c|c|c|c|c|c|}
\hline Linguagem artística & Artes Visuais & Música & Teatro & Dança & Total \\
\hline $\begin{array}{c}\text { Número de provas que ofertaram } \\
\text { mais questões por linguagem } \\
\text { artística }\end{array}$ & 17,0 & 1,5 & 1,5 & 0,0 & 20,0 \\
\hline
\end{tabular}
Fonte: Tabela elaborada pela autora com base nas provas objetivas coletadas

A tabela 3 apresenta dados referentes às provas objetivas que ofertaram as quatro linguagens artísticas de forma conjunta (20), e nesta é possível verificar que além da oferta de questões relativas às Artes Visuais ser muito superior em relação às outras linguagens artísticas, observa-se que a Dança não chegou a ter o número maior de questões nenhuma vez. Pelo contrário, ela foi, na maior parte das vezes, ignorada ou inseriram apenas uma questão sobre o assunto. Quanto a este fato, parece que a banca examinadora apenas visou alcançar um efeito "simbólico" haja vista os dados referentes a outras questões.

No que se refere às linguagens da Música e do Teatro, esta última teve 9 questões ofertadas no concurso realizado no RJ no ano de 2010, contra 7 de música e 4 de Artes 
Visuais e nenhuma de Dança. Quanto à Música, esta teve a maior quantidade ofertada no Estado do Distrito Federal, sendo 3 questões de Música contra nenhuma (0) nas outras três linguagens artísticas. O empate entre o maior número de questões de Música e Teatro ocorreu no Amapá, onde foi ofertado 7 questões para cada, 6 para Artes Visuais e nenhuma para Dança.

A partir da análise, constatamos que fica evidente certo privilégio em relação à oferta de questões relativas às Artes Visuais, pois a diferença entre a oferta de questões desta última em relação às outras três linguagens artísticas é muito maior, ou seja, a desproporção é clara. Tal fato faz com que as pessoas formadas em Artes Visuais tenham certa vantagem em relação aos outros candidatos inscritos nas provas de concurso público em Artes.

\section{Considerações finais}

Conforme o exposto, e com base nas provas analisadas, constatamos que pouquíssimos (2) concursos públicos para professor de Arte da Educação Básica em diferentes estados brasileiros consideraram a linguagem artística de formação do professor de arte, ofertando-as separadamente na prova objetiva, a saber: Acre e Goiás. Vimos que a maioria das provas dos concursos ofertam questões sobre as quatro linguagens artísticas conjuntamente. E que as pessoas formadas em Artes Visuais tiveram certo privilégio quando realizaram essas provas, pois havia maior número de questões nessa linguagem do que nas outras três. Porém, ainda assim, mesmo com esse "privilégio", consideramos injusto a pessoa formada numa linguagem artística específica precisar saber questões de outras linguagens que não a da sua formação.

Ressaltamos aqui que não somos contra a interdisciplinaridade e/ou a transdisciplinaridade, porém se o inscrito não vivencia essa forma de aprendizagem durante sua formação inicial, através de relações com as outras linguagens artísticas, provavelmente não estará apto a responder questões com essas características. Ademais, a maioria das provas analisadas apresentam questões com um viés multidisciplinar e por vezes interdisciplinar ou transdisciplinar, como vimos nos exemplos anteriores e também na tabela 2. Ou seja, o futuro professor de Arte terá que responder questões muito específicas de linguagens artísticas que desconhece, o que provavelmente o prejudicará.

Podemos afirmar que um dos motivos para que os concursos públicos destinados aos professores da Educação Básica, especialmente na área de Arte, continuem requisitando que os professores conheçam as quatro linguagens artísticas pode estar ligado ao fato 
dos organizadores dos concursos se basearem nos PCN (1997), ou até mesmo em algumas diretrizes e/ou propostas curriculares estaduais de Arte que foram criadas antes da maioria das licenciaturas na área de arte se separarem em linguagens artísticas específicas, ou ainda, pelo simples fato de não haver divisão destas na Educação Básica, sendo ofertada apenas uma disciplina com a nomenclatura 'Arte', seguindo a denominação utilizada pela LDB 9.394/9612. Apesar de tudo isso, os cursos de licenciatura na área de arte, em geral, se dividiram, por isso, consideramos de suma importância que as provas dos concursos públicos sejam de acordo com a linguagem de formação do inscrito.

Assim que o Projeto de Lei (PL) 7.032/10 for aprovado em definitivo, este poderá resolver a problemática das quatro linguagens artísticas sendo ofertadas de forma conjunta nas provas dos concursos, pois o mesmo propõe que para atuação docente o professor tenha formação específica em uma das quatro linguagens artísticas. Segundo Alvarenga (2013) esse PL alterará a denominação 'arte' presente na atual LDB, manterá a linguagem da música como conteúdo obrigatório (lei 11.769/2008) e adicionará a dança, o teatro e as artes visuais; ou seja, esse PL representa o fim da indefinição do que é entendido pela palavra arte na atual legislação e institui a necessidade de contratação de profissionais formados de acordo com cada linguagem artística. Mas, enquanto esse PL não é aprovado em definitivo e implementado:

Propomos que as diversas associações da área de Artes reflitam e ajam de forma conjunta para reivindicar que as provas dos concursos para a disciplina de Arte na Educação Básica sejam ofertadas de acordo com a linguagem artística específica do inscrito. Consideramos que é importante ter uma base comum com questões sobre o ensino da arte e leis que afetaram/afetam a disciplina de arte na educação básica, assim como questões que abordem as relações entre as diferentes linguagens artísticas. Porém, é necessário que exista, no conjunto das questões propostas, uma parte destinada a questões específicas de acordo com a formação do futuro professor de arte, pois este deve ter sua formação inicial respeitada. (ALVARENGA, 2014, p.798).

Consideramos que tal estrutura permitirá que todos os inscritos nesses concursos públicos para professor de Arte na Educação Básica, mesmo tendo se formado num curso com características polivalente ou num curso com linguagem artística específica, poderão realizar uma prova mais justa e de acordo com o que de fato vivenciou durante seu curso de licenciatura.

\footnotetext{
${ }^{12}$ A atual LDB também apresenta a Música como conteúdo obrigatório, tal como vimos anteriormente.
} 


\section{Referências}

ALCÂNTARA, Daniel Moreira. Questões de artes nas provas dos processos seletivos públicos municipais em Pernambuco (2009-2011). In: XXII CONFAEB Arte/Educação: Corpos em Trânsito 29 de outubro à 02 de novembro de 2012 Instituto de Artes / Universidade Estadual Paulista. Disponível em: http://faeb.com.br/livro03/Arquivos/comunicacoes/411.pdf Acesso em: 02/02/2015.

ALVARENGA, Valéria Metroski. O Projeto de Lei 7.032/10 prevê linguagens artísticas separadas na Educação Básica: será o fim da polivalência? Linguagens - Revista de Letras, Artes e Comunicação, Blumenau, v. 7, n. 3, p. 261-275, set;/dez. 2013.

. Qual a situação das artes visuais nos concursos públicos para professores de arte na educação básica? $23^{\circ}$ Encontro da ANPAP - "Ecossistemas Artísticos" 15 a 19 de setembro de 2014 - Belo Horizonte - MG, pp. 785-799. Disponível em:

http://www.anpap.org.br/anais/2014/ANAIS/Comit\%C3\%AAs/2\%20EAV/Val\%C3\%A9ria \%20Metroski\%20de\%20Alvarenga.pdf Acesso em: 30/01/2015.

BARBOSA, Ana Mae. Arte-Educação no Brasil - Realidade hoje e expectativas futuras. Estudos Avançados, vol.3 no. 7 São Paulo, Set./Dez. 1989.

BRASIL. MEC. Conselho Nacional de Educação/ Câmara de Educação Superior. Parecer Diretrizes Curriculares Nacionais para os Cursos de Graduação em Artes Visuais de Bacharelado e Licenciatura. Distrito Federal, 2007.

BRASIL. Lei 11.769/2008. Altera a Lei no 9.394, de 20 de dezembro de 1996, Lei de Diretrizes e Bases da Educação, para dispor sobre a obrigatoriedade do ensino da música na educação básica. Disponível em: http://www.planalto.gov.br/ccivil_03/_Ato20072010/2008/lei/L11769.htm Acesso em: 09/06/2014.

CEARÁ, Governo do Estado do. Secretaria da Educação - Concurso Público: Caderno de provas objetivas - 2013.2 Arte. Disponível em: http://site.pciconcursos.com.br/provas/19399935/1c59c59b4468/p_arte_educa_o.pdf Acesso em: 03/02/2015.

GATTI, Bernardete Angelina. Estudos quantitativos em Educação. In: BERNARDETE A. Gatti. / organização Walter E. Garcia; textos selecionados de Bernardete A. Gatti. Belo Horizonte: Autêntica Editora, 2011. (Coleção Perfis da Educação).

PARÁ, Governo do Estado do. Secretaria de Estado de Educação, Concurso Público para provimento de vagas de nível superior e fundamental - professor Artes. 2009. Disponível em: 
http://site.pciconcursos.com.br/provas/13818625/a9e5f4557fa9/411seduc_2009_artes.p df Acesso em: 03/02/2015.

PCI CONCURSOS. Provas para Download. Disponível em: http://www.pciconcursos.com.br/provas/professor-de-arte Acesso em: 09/05/2014.

SÃo PAULO, Governo do Estado de. Secretaria de Estado da Educação Coordenadoria de gestão de recursos humanos, Concurso Público para professor de educação básica II. Prova de conhecimentos específicos - Arte. 2013. Disponível: http://site.pciconcursos.com.br/provas/19691132/d884f76c4999/nsce01_001_artes_tipo 201.pdf Acesso em: 03/02/2015.

ZABALA, Antoni. A prática educativa: como ensinar /Antoni Zabala; trad. Ernani F. da F. Rosa - Porto Alegre: Artmed, 1998.

'Mestranda em Artes Visuais pela Universidade do Estado de Santa Catarina (UDESC) e

Recebido em: 16/06/2014

Aprovado em: 16/01/2015 